\title{
Mechanical homeostasis in tissue equivalents: a review
}

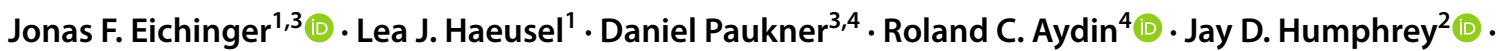 \\ Christian J. Cyron ${ }^{3,4}$ [
}

Received: 12 October 2020 / Accepted: 4 February 2021 / Published online: 8 March 2021

(c) The Author(s) 2021

\begin{abstract}
There is substantial evidence that growth and remodeling of load bearing soft biological tissues is to a large extent controlled by mechanical factors. Mechanical homeostasis, which describes the natural tendency of such tissues to establish, maintain, or restore a preferred mechanical state, is thought to be one mechanism by which such control is achieved across multiple scales. Yet, many questions remain regarding what promotes or prevents homeostasis. Tissue equivalents, such as collagen gels seeded with living cells, have become an important tool to address these open questions under well-defined, though limited, conditions. This article briefly reviews the current state of research in this area. It summarizes, categorizes, and compares experimental observations from the literature that focus on the development of tension in tissue equivalents. It focuses primarily on uniaxial and biaxial experimental studies, which are well-suited for quantifying interactions between mechanics and biology. The article concludes with a brief discussion of key questions for future research in this field.
\end{abstract}

Keywords Mechanical homeostasis · Tensional homeostasis · Mechanobiology $\cdot$ Mechanoregulation ·

Mechanotransduction $\cdot$ Mechanosensation $\cdot$ Growth and remodeling

\section{Introduction}

The important role of mechanics in governing biological form and function has been known since the time of Galileo Galilei (1564-1641) and Giovanni Borelli (1608-1667), that is, for at least four centuries (Cyron and Humphrey 2017; Piolanti et al. 2018). Yet, it was only about a century ago that Henry Gassett Davis and Julius Wolff succeeded in condensing this general notion into two precise statements, Davis' law in 1867 and Wolff's law in 1892, which established relations between mechanical loading and growth and remodeling (G\&R) in soft and hard tissues, respectively (Davis 1867; Wolff 1892). Building on the ideas of Claude Bernard

Christian J. Cyron

christian.cyron@tuhh.de

1 Institute for Computational Mechanics, Technical University of Munich, 85748 Munich, Germany

2 Department of Biomedical Engineering, Yale University, New Haven, CT 06520, USA

3 Institute of Continuum and Materials Mechanics, Hamburg University of Technology, 21073 Hamburg, Germany

4 Institute of Material Systems Modeling, Helmholtz-Zentrum Geesthacht, 21502 Geesthacht, Germany in 1865 (Bernard 1865), Walter Cannon introduced the central concept of homeostasis in the 1920s (Cannon 1929), as summarized in the influential book "The Wisdom of the Body" in 1932 (Cannon 1932), which introduces the concept of homeostasis as "coordinated physiological reactions which maintain most of the steady states in the body". These laws and concepts can be considered as landmarks paving the way to modern mechanobiology by exposing the fundamental importance of mechanically regulated processes for tissue health and disease.

Due to rapidly improving experimental and computational techniques and technologies, substantial progress has been made in mechanobiology, especially since the mid1970s. A corner stone of nearly all approaches is the hypothesis that there exists a preferred mechanical state-often referred to as homeostatic - toward which mechanobiological activity is targeted. This generally accepted assumption goes back at least to the mid-1960s and the seminal study of Wolinsky and Glagov (1967), which showed that the aorta in various mammals develops such that the tension per medial lamellar unit is nearly the same $(\sim 2 \mathrm{~N} / \mathrm{m})$, implying a "target" value of medial stress on the order of $10^{2} \mathrm{kPa}$. Twenty years later, Bissel and Aggeler (1987) introduced the concept of dynamic reciprocity, presenting the idea of 
dynamic feedback loops between cells and the surrounding extracellular matrix (ECM) that ensure that this target state is maintained within a certain tolerance. Since then, changes in the mechanical properties of the ECM have been shown to effect crucial cellular processes such as migration (Grinnell and Petroll 2010; Hall et al. 2016; Xie et al. 2017; Kim et al. 2019), differentiation (Chiquet et al. 2009; Mammoto et al. 2012; Zemel 2015), and even survival (Bates et al. 1995; Zhu et al. 2002; Schwartz 2002; Sukharev and Sachs 2012) (outside-in effect). Conversely, cells establish tissue form and function during development, maintain tissue integrity in health, and adapt tissue in response to perturbations such as injury or disease (Cox and Erler 2011; Lu et al. 2011; Ross et al. 2013; Bonnans et al. 2014; Humphrey et al. 2014a) (inside-out effect). In short, cells are equipped with the complementary processes of mechanosensation and mechanoregulation which are assumed to be crucially involved in the promotion of tissue health and proper functionality. Cells constantly perceive cues from their extracellular environment, transduce them into intracellular signals, and react, for example, by adapting their contractile state. Transmembrane receptors such as integrins physically connect the actin cytoskeleton inside the cell to fibers of the ECM and thus enable the transfer of mechanical loads (Jiang et al. 2006; Cavalcanti-Adam et al. 2007; Lerche et al. 2019).

Among the many different experimental approaches for studying the cell-matrix interactions that govern such biological form and function, tissue equivalents have emerged as particularly useful. Often formed as reconstituted collagenor fibrin-based gels, cell-seeded tissue equivalents are typically meant to be simple in vitro model systems, not ex vivo tissue-engineered materials for implantation in regenerative medicine. Our focus is on the use of tissue equivalents for studying the underlying mechanobiology; we leave to others the review of tissue-engineered constructs, often beginning as cell-seeded polymeric scaffolds. We note, nonetheless, that some investigators use the term tissue-engineered to describe tissues fabricated for basic science studies, including via decellularization and subsequent cell-seeding, and that have revealed important mechanobiological effects, as, for example, that aberrant matrix can corrupt the behavior of otherwise normal cells (Sewanan et al. 2019).

In a seminal paper on tissue equivalents, Brown et al. (1998) wrote: "We would define tensional homeostasis as the control mechanism by which fibroblasts establish a tension within their extracellular collagenous matrix and maintain its level against opposing influences of external loading." This definition reflected well their specific observations in fibroblast-seeded collagen gels under particular conditions and further highlighted the importance of homeostasis in mechanobiology. With an additional twenty-plus years of hindsight, Stamenović and Smith (2020) wrote, "we define tensional homeostasis as the ability to maintain a consistent level of tension, with a low variability around a set point, across multiple length scales." This latter definition is closer in concept to that put forth by Cannon $(1929,1932)$ who introduced the word homeostasis, noting his careful choice of the prefix "homeo" (derived from the ancient Greek "homoios" meaning "similar", thus allowing some variation) rather than "homo" (derived from the ancient Greek "homos" meaning the "same", implying rigid constancy). Some accounts in the literature appear to misinterpret data within this framework by ignoring the possibility of maintaining a steady state within a range, perhaps in part because the allowable extent of such a range is not easily known. We emphasize, further, that it is not yet clear what the cells sense (force, extension, stiffness, compliance, etc.), though it is clear that some cells are more responsive to shearing loads (endothelial), some to tensile loads (fibroblasts), and some to compressive loads (chondrocytes). Hence, we suggest that "tensional homeostasis" is too narrow of a definition, with possible further ambiguities arising due to individual interpretations of what a tension is: a tensile force (units of $\mathrm{N}$ ), an actual tension (units of $\mathrm{N} / \mathrm{m}$, as in surface tension), or a tensile stress (units of $\mathrm{N} / \mathrm{m}^{2}$ ). For these and other reasons, we prefer "mechanical homeostasis" as a more general term to encompass different responses by different cell types under different conditions and to acknowledge that we as a community continue to seek what cells sense and regulate. One can thus define mechanical homeostasis broadly as a ubiquitous mechanobiological process by which soft tissues seek to maintain key regulated variables within a range near a preferred value, often called a homeostatic target or set-point. Importantly, homeostatic targets or ranges adapt in some cases (Davies 2016) and additional terms, including allostasis and rheostasis, have been used in such cases in different fields, including those focusing on different types of stressors (e.g., emotional stress; McEwen and Wingfield 2010). Alternatively, homeostatic targets or ranges can be overridden in other cases, including chronic inflammation (Chovatiya and Medzhitov 2014). Indeed, it has been suggested that it is the very adaptivity of homeostatic targets that renders particular biological systems susceptible to override and thus to particular diseases (Kotas and Medzhitov 2015). Notwithstanding the important roles of the immune system in promoting or preventing mechanical homeostasis, particularly by macrophages (Wynn et al. 2013; Okabe and Medzhitov 2016), we focus herein on mechanobiological responses over modest ranges from normal by cells such as fibroblasts, which have primary responsibility for establishing, maintaining, remodeling, and repairing extracellular matrix (Tomasek et al. 2002).

Awareness of the importance of mechanobiology and in particular mechanical homeostasis continues to grow in medicine and biomedical engineering. Some of the most important causes of mortality and morbidity in 
industrialized countries are closely linked to mechanobiology. These include diverse cardiovascular diseases and cancer (Weaver et al. 1997; Boettiger et al. 2005; Yeung et al. 2005; Weninger et al. 2009; Butcher et al. 2009; Lu et al. 2012). For example, thoracic aortic aneurysms appear to arise in part from dysfunctional mechanosensing or mechanoregulation of the ECM (Humphrey et al. 2014b), whereas abdominal aortic aneurysms (AAAs) (Fig. 1a, b) may experience continued enlargement due to mechanobiological instabilities (Cyron and Humphrey 2014; Cyron et al. 2014). While advances in medical imaging have increased the number of diagnosed aneurysms, a comprehensive understanding of their initiation and natural history, ranging from the sub-cellular to the organ scale, still remains elusive. There exists, therefore, a considerable opportunity to use allied methods, including in vitro studies of tissue equivalents (Fig. 1). Model systems-typically cell-seeded fibrin (Sander et al. 2011) or collagen (Sander and Barocas 2008) gels-are much simpler and therefore suitable for precise quantitative in vitro studies of cell-matrix interactions due to a greatly reduced number of confounding factors and interdependencies (Fig. 1c, d).

In this article, we review the current understanding of mechanical homeostasis in three-dimensional, gel-based tissue equivalents by summarizing and comparing results gained in different types of tissue culture experiments.
Finally, we discuss limitations of the available data, raise open questions, and consider future directions of this emerging field of research.

\section{Using tissue equivalents to study mechanical homeostasis in soft tissues}

Mechanobiology focuses on understanding effects of mechanical stimuli on particular cellular actions. To study this, both the stimulus and the response need to be measurable and controllable; in other words, it is best to design experiments representing simple boundary and initial value problems that simplify data analysis and interpretation. Toward this end, in vitro studies using planar (rectangular or annular) or cylindrical tissue equivalents have been preferred. It is worth highlighting that cells in three-dimensional in vitro environments such as collagen or fibrin gels behave differently compared to those exposed to two-dimensional in vitro environments. The latter include micro-patterned substrates such as petri dishes made of plastic or glass coated with collagen or fibronectin. While such two-dimensional setups are simple, they cannot adequately mimic several important factors of the physiological environment in vivo. In fact, the dimensionality of the substrate interacting with cells has been shown to crucially influence
Fig. 1 Cell-seeded collagen gels as tissue equivalents can provide information relevant to mechanical homeostasis of soft tissues. a Illustration of a patient with a local dilatation of the aorta (i.e., an aneurysm); due to ill-controlled mechanobiological processes; such aneurysms can continue to grow over years and often finally rupture, resulting in high mortality and morbidity; $\mathbf{b}$ in vivo studies often cannot provide the fine control needed to assess the cell-ECM interactions that are fundamental to promoting or preventing homeostasis, and thus understanding disease progression. c Cell-seeded collagen or fibrin gels have proven to be simple but powerful model systems to study soft tissue mechanobiology. d The much lower complexity of cell-seeded collagen gels compared to native ECM makes them useful for studying the fundamental cell-matrix interactions, often one cell type at a time

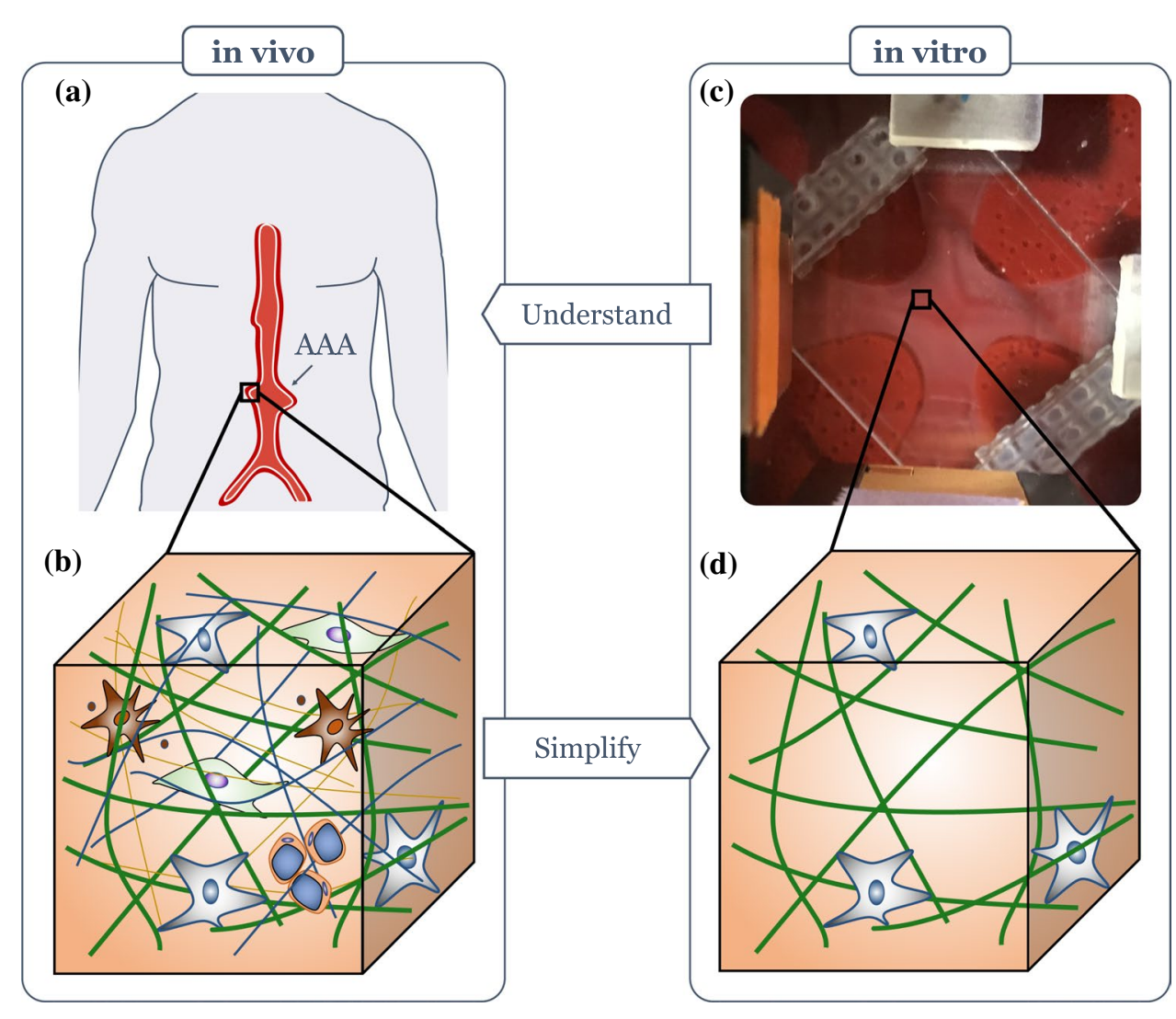


cellular processes such as cell proliferation, survival, differentiation, and migration; see Baker and Chen (2012), Friedl et al. (2012), and Bonnier et al. (2015). For a review of two-dimensional versus three-dimensional culture environments, see Baker and Chen (2012) and Duval et al. (2017). The studies with three-dimensional tissue equivalents can be classified further by the mechanical boundary conditions imposed experimentally. So far, free-floating (mostly circular), uniaxially constrained or extended, and biaxially constrained or extended cell-seeded gels have been used in most experiments (Fig. 2). Cylindrical tissue equivalents that generate hoop stresses and circumferential fiber alignment if set around a non-adhesive mandrel have been used similarly (Barocas et al. 1998; Isenberg et al. 2006), but are less common and are not discussed in detail here. In most cases, cylindrical geometries are motivated by tissue engineering applications, including vascular grafts.

\subsection{Circular free-floating tissue equivalents}

First, free-floating collagen discs were introduced by Bell et al. (1979), who showed that the gels compact significantly $(\sim 90 \%$ Fig. 2 a) due to cellular mechanobiological activity over a period of days. Free-floating discs are experimentally simple to create and handle and thus are favorable for qualitative studies (Steinberg et al. 1980; Buttle and Ehrlich 1983; Grinnell and Lamke 1984; Ehrlich et al. 1986; Woodley et al. 1991; Schiro et al. 1991; Kelynack et al. 2000; Ehrlich and Rittenberg 2000; Grinnell 2000; Grinnell and Ho 2002; Redden and Doolin 2003; Orlandi et al. 2005; Stevenson et al. 2010; Grinnell and Petroll 2010). Nevertheless, due to the relatively complex residual stress fields that develop (Simon et al. 2012, 2014), it can be challenging to determine key parameters or mechanisms of soft tissue mechanobiology quantitatively from experiments with free-floating discs. For example, as mentioned before, one key question is how mechanical stimuli are transduced and then drive cellular actions via corresponding signaling pathways. To obtain a quantitative understanding of this problem, experiments are required where both the mechanical loads and the subsequent cellular responses can be quantified accurately. Given that prior studies using free-floating gels have not interpreted regional cellular responses in terms of the complex inhomogenous stress field (compressive and tensile stresses, which induce regional anisotropies), this review focuses instead on uniaxial and biaxial testing studies, which were introduced several decades after the first free-floating gels were studied, in part, to overcome limitations of the latter. For a review of free-floating collagen gels, see Dallon and Ehrlich (2008) and Simon and Humphrey (2014). Here, therefore, we turn our attention to uniaxial and biaxial studies wherein stress/strain fields can be homogeneous if studied sufficiently far from the end-effects at the boundaries.

\subsection{Uniaxially constrained tissue equivalents}

General setup For quantitative studies of how cells respond to external mechanical loading, uniaxially constrained or extended tissue equivalents (Fig. 2b) were developed. Unlike free-floating gels, uniaxial setups exhibit a largely homogeneous tension field (within the central region), with measurements of the net uniaxial loading straightforward. (a)

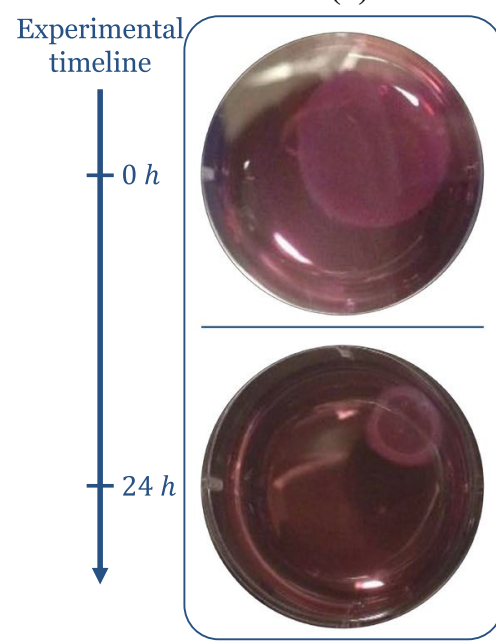

(b)

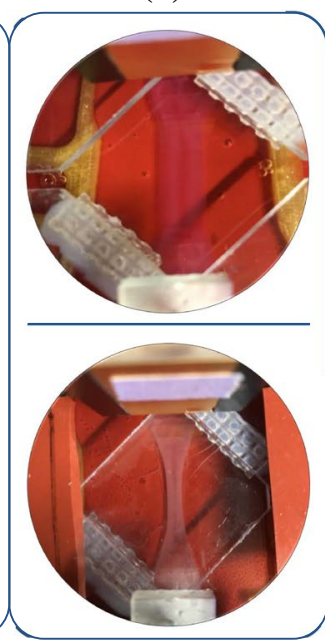

(c)

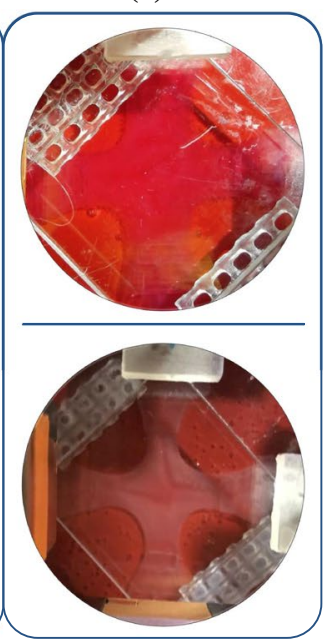

(d)

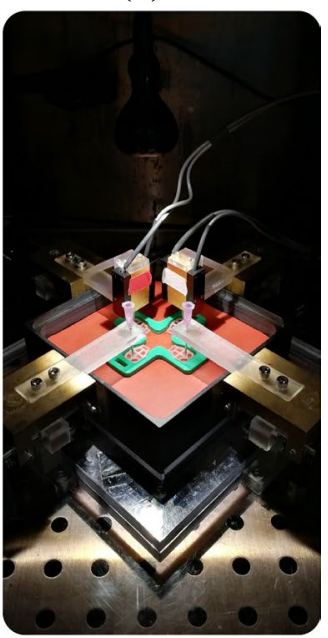

Fig. 2 Free-floating (a), uniaxially constrained (b), and biaxially constrained (c) fibroblast-seeded collagen gels (i.e., tissue equivalents) are observed to contract substantially over the first hours to days. Cells residing in the gel initially spread and attach to surrounding collagen fibers. Cellular contraction then compacts the surrounding matrix thus stressing the fibers. d Biaxial testing device reported in Eichinger et al. (2020). Sensors are installed along two axes to record the development of tension in a cruciform gel 
This makes it easier to quantify how a certain mechanical target state evolves over time, and if and how it is restored after perturbations. Most uniaxial experiments with tissue equivalents follow a similar approach. First, a gel is fabricated by combining collagen, cells, Dulbecco's modified Eagle's medium (DMEM), a buffer, and an antibiotic (for more details, see supplementary Tables S1 and S2). The collagen solution is then cast into a rectangular mold within a device where it sets around two insets, one of which can be connected to a motor that can impose uniaxial strain. The other inset, residing on the opposite side of the gel, is connected to a force transducer such that forces imposed on or generated within the gel can be measured. Typically, the gel is initially free of mechanical load. If, however, the total length of the gel is kept constant by the device, one observes that a substantial tension builds up over a period of several hours due to cell-mediated contraction of the gel (phase I), often reaching a steady state (phase II) (Fig. 3). This steady state is often referred to as a homeostatic state- thus reflecting Brown's tensional homeostasis. As the tissue evolves, the initial rectangular shape of the gel typically changes to a more dog-bone like shape because cell-mediated contraction acts not only along the gel axis, but also transversely, where it is not impeded as the lateral surface remains traction-free (Fig. 2b). Studies with tissue equivalents in such a uniaxial setting have addressed in particular the following aspects so far.

Mechanical homeostasis In contrast to classical engineering materials, living soft tissues apparently seek to establish and maintain a preferred mechanical state that is not stress-free. Delvoye et al. (1991) were the first to show that uniaxially constrained collagen gels seeded with dermal fibroblasts exhibit a characteristic behavior with the aforementioned two distinct stages. During the first $6-12 \mathrm{~h}$, a tensile force increases rapidly (phase I) before entering a steady state ('homeostatic state') with neither further increase nor decrease (phase II). When this tension is perturbed by slightly stretching or releasing a gel that has already reached phase II, tension returns toward the prior level within around $1 \mathrm{~h}$. To date, it remains controversial within what tolerance the prior level is restored, mainly or only to some extent, but we must recall here Cannon's particular choice of the prefix homeo, meaning "similar", not "the same". The two stages observed by Delvoye et al. (1991) were confirmed by Eastwood et al. (1994, 1996), who found that even cell-free constrained collagen gels tend to build up some tension during the first few hours of maturation, presumably due to entanglement and cross-linking of fibers in the gel. As noted earlier, it was a few years later that this group coined the terminology "tensional homeostasis" to describe their observations in these uniaxially constrained, fibroblast-populated gels under particular fabrication and culture conditions. Namely, they examined cell-populated collagen-glycosaminoglycan sponges subjected to different loading protocols, including cyclical over- and underloading, cyclical median loading, and cyclical incremental loading, to study reactions of the gels triggered by these diverse external stimuli. When gels were subjected to a sudden stretch or release, gels were observed to return toward their prior tension level in the following $15 \mathrm{~min}$. Especially
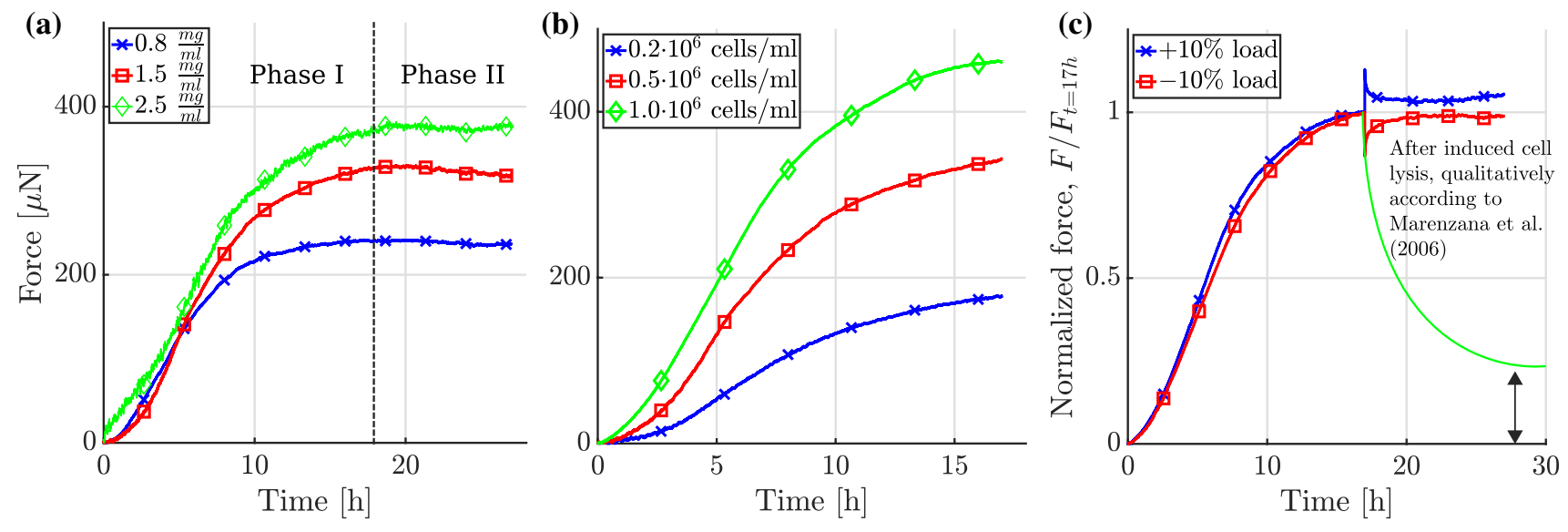

Fig. 3 In uniaxially constrained tissue equivalents, the measured tensile force evolves in two characteristic phases: a steep increase (phase I) followed by a plateau (phase II). Here, we show experimental data from Eichinger et al. (2020). Each curve is an average of three identical experiments. a Dependence of the plateau value of tension on collagen concentration in the gel with a constant cell density of $0.5 \cdot 10^{6} \mathrm{cells} / \mathrm{ml}$. Higher collagen concentrations lead to higher steady state values. b Influence of cell density for a collagen concentration of $1.5 \mathrm{mg} / \mathrm{ml}$ : Higher cell densities lead to both a steeper initial increase and a higher plateau value of the measured force. $\mathbf{c}$ If the tissue equivalent (collagen concentration $1.5 \mathrm{mg} / \mathrm{ml}$, cell density $1.0 \cdot 10^{6}$ cells $/ \mathrm{ml}$ ) is suddenly stretched or released after having reached the plateau state, force returns toward its value prior to this perturbation. The monotonically decreasing force qualitatively illustrates the expected evolution in case of cell lysis according to Marenzana et al. (2006); the fraction of the tensile force remaining in the gel has been called residual matrix tension (RMT) 
notable is that the tension in the gels was observed to reincrease immediately after release, which led the authors to the conclusion that viscoelastic effects alone are not sufficient to explain the observed behavior.

The two characteristic stages of this so-called tensional homeostasis and the tendency of tissue equivalents to restore their prior tension level after perturbation were confirmed by Ezra et al. (2010). They observed the homeostatic state to arise during the first $8 \mathrm{~h}$. When this state was perturbed by a series of alternate stretch and release steps every 30 min, tension was observed to return toward the prior value during the 30 min between two consecutive perturbation steps. However, the 30 min relaxation periods between two subsequent perturbations were too short to answer the question within which tolerance the homeostatic state is restored after a perturbation. Generally, Ezra et al. (2010) found that gels reacted more strongly to perturbations if their amplitude was higher. Very similar results were reported by Bisson et al. (2009), where gels were observed to counteract uniaxially applied loads. In cases of reduced loading, gels reacted by increasing tension; in cases of increased loading, gels reacted by decreasing tension. Furthermore, it was observed that fibroblasts from diseased fibrotic tissue did not replicate the aforementioned characteristic two-stage behavior-steep increase of tissue tension (phase I) followed by a plateau (phase II), because they failed to reach the second stage characterized by steady state at least within the same time interval.

The observations summarized above were further supported by Marenzana et al. (2006), who studied the effect of cytochalasin D. This agent disrupts the actin cytoskeleton and thereby eliminates active cellular contraction from the gel. When added to the culture medium after $24 \mathrm{~h}$, when the homeostatic state had been reached, it induced a rapid and total decline of the tension in gels populated with human dermal fibroblasts. No residual matrix tension (RMT) was measured in this case. Interestingly, in gels populated with fibroblasts from rat tendon, a substantial residual tension was observed even $12 \mathrm{~h}$ after treatment with cytochalasin D. Hypo-osmotic cell lysis via replacement of the culture medium with distilled water gave similar results regarding the measurable RMT. When comparing the results of adding cytochalasin D after $4 \mathrm{~h}$ and after $60 \mathrm{~h}$ in culture, RMT seemed to increase linearly with time in culture, making up a growing fraction of the tension before treatment. RMT was also higher when gels had been exposed to cyclical loading. Moreover, it was shown that cell-seeded collagen gels after $24 \mathrm{~h}$ had a significantly higher stiffness than cell-free gels after the same time in culture. Collectively, these observations suggest that at least certain types of fibroblasts, such as the ones from rat tendon, remodel the matrix surrounding them in a way that is not purely elastic (Yamato et al. 1995; Sawhney and Howard 2002). Such cells rather appear to start by elastically contracting their surrounding gel; subsequently, they seem to entrench an increasing fraction of this tension, possibly because this is energetically more favorable than maintaining it over a prolonged time by active cellular tension. It remains an open question why cyclical loading increases RMT. It is noteworthy that Kolodney and Wysolmerski (1992) did not observe any RMT for chick embryo fibroblasts or endothelial cells, despite following an approach very similar to the one of Marenzana et al. (2006). This further supports the hypothesis that the entrenchment of matrix tension-perhaps via physical entanglements, but also via matrix cross-linking via transglutaminases (when remodeled) or lysyl oxidases (when synthesized) as noted before (Simon et al. 2014)_depends on the cell type and experimental conditions, including the type of matrix used to constitute the gel and the culture media (e.g., whether containing copper or not, noting that enzymes such as lysyl oxidase are copper dependent).

Influence of cell density and matrix composition on tension When using both calf skin fibroblasts (Delvoye et al. 1991) and NIH 3 T3 fibroblasts (Eichinger et al. 2020), tension in the homeostatic state of uniaxial tissue equivalents increases linearly with collagen concentration. Notably, Eichinger et al. (2020) demonstrated that higher collagen concentrations increase the steady state tension but not the rate at which tension is built up initially. Moreover, tissue tension increases with cell density, either linearly (Delvoye et al. 1991; Eichinger et al. 2020) or nonlinearly (Legant et al. 2009; Jin et al. 2015) depending on the experimental conditions.

Increasing the collagen concentration also increases the gel stiffness (Alcaraz et al. 2011; Miroshnikova et al. 2011; Hall et al. 2016; Joshi et al. 2018). Therefore, one may hypothesize that the reason for the effect of the collagen concentration on the homeostatic tension is that cells often tend to respond more to a stiffer mechanical environment by increasing contraction (Ghibaudo et al. 2008; Califano and Reinhart-King 2010; Schiller and Fässler 2013; Cheng et al. 2013; Oria et al. 2014; Zhu et al. 2016). This hypothesis is supported by observations of Zhao (2014), who statically prestretched microtissues, which increased their stiffness, and subsequently observed higher cell-mediated tissue tension. It is interesting to note that the alignment of fibers and cells by static loading can reorganize the tissue, which can increase its anisotropic strength, stiffness, and ability to contract (Grenier et al. 2005). In general, mechanical homeostasis is promoted by the cells not only under static but also under dynamic loading (Walker et al. 2020), which can thus also be used to alter tissue stiffness.

It is noteworthy that Karamichos et al. (2007) reported that human dermal fibroblasts produced a much lower homeostatic tension and also a much slower development of the homeostatic tension plateau if exposed to an initially 
prestretched matrix. This effect was the more pronounced the higher the initial prestretch. Given that prestretch stiffens the collagen matrix, these observations may seem at first glance a contradiction to the ones of Delvoye et al. (1991), Zhao (2014), and Eichinger et al. (2020). Yet, both may be brought into agreement by noting that cells have been found to respond to changes in stiffness in a biphasic manner (Chan and Odde 2008), that is, there may exist a certain regime where cellular tension increases with the stiffness of the mechanical environment and another regime where the opposite is true. A similar phenomenon is also known for cell migration (Bangasser et al. 2017).

It has been shown that the effective stiffness that is sensed by the cells and that is determined by the matrix stiffness and the stiffness of the boundary (noting that stress and stiffness fields can often be computed away from the end effects, but cells near the boundaries yet sense and respond to their local environment) needs be considered for mechanoregulation (Kural and Billiar 2016). In particular, Legant et al. (2009) observed that both a higher gel stiffness and a stiffer fixation of the tissue at the boundary led to a higher cell-mediated tension in the tissue.

Role of cell type and tissue origin Multiple studies have shown that both the type of the cells used in tissue equivalents as well as the type of tissue from which they have been extracted affect the homeostatic tension. Delvoye et al. (1991) reported that calf dermal fibroblasts produced higher tension than human dermal fibroblasts. Active tension generated by chick embryo fibroblasts was found to be higher than that generated by a monolayer of human umbilical vein endothelial cells (Kolodney and Wysolmerski 1992). It is possible that the latter is not a consequence of the different cell type but rather because the endothelial cells were seeded on the surface of pre-polymerized gels, not embedded within the gel. On the other hand, it is also noteworthy that the endothelial cells reached their homeostatic state only after 4-5 days, whereas the fibroblasts did so in less than $24 \mathrm{~h}$, which may indicate a more pronounced contractile activity of the fibroblasts. Interestingly, neither the chick embryo fibroblasts nor the endothelial cells entrenched any RMT, proven by a rapid decay of the tension to zero after addition of Cytochalasin D. By contrast, Marenzana et al. (2006) reported RMT for rat tendon fibroblasts as mentioned above, which suggests that generation of RMT may depend on factors not yet fully understood. Also Eastwood et al. (1996) demonstrated considerable dependency on the cell type and cell line for both the level of homeostatic tension and the rate at which it is built up initially. Rabbit tendon fibroblasts, for example, only started contracting after $14 \mathrm{~h}$ in culture and produced much less tension than human dermal fibroblasts. It was also found that there is a difference in homeostatic tension between human dermal fibroblasts from the same tissue sample depending on whether the fibroblasts were grown by explant migration or extracted by bacterial collagenase digestion. Fibroblasts grown from explants generated a tension approximately $60 \%$ higher than the one generated by fibroblasts extracted with collagenase. This effect was attributed to a natural selection bias. The cells that migrated most strongly were favored by the explant growth extraction process so that this process selected a sub-population of cells that distinguished itself by unusually strong cellular contractility. Note that Ezra et al. (2010) studied mechanical homeostasis with occular fibroblasts from individuals with and without floppy eyelid syndrome. The latter is associated with a reduced stiffness of the tarsal plate and thus a supposedly higher (dynamic) tension in vivo. Interestingly, fibroblasts from individuals with floppy eyelid syndrome were also observed to establish a higher homoestatic tension when extracted from their natural environment and studied in vitro. A possible explanation for this is that cells may alter their homeostatic target state when exposed to altered mechanical or possibly biochemical conditions over a prolonged period. Such a possibility is consistent with a generalized concept of adaptive homeostasis (Davies 2016).

Porcine smooth muscle cells from different layers of the pulmonary artery were found to establish (within around one day) a homeostatic tension at different speeds and with different magnitudes. Both were higher for cells from the outer medial layer than for cells from the inner medial layer (Hall et al. 2007). The tension generated by fibroblasts from different regions of the human eye were studied by Dahlmann-Noor et al. (2007). Corneal fibroblasts established a much higher tension than fibroblasts from Tenon's layer. The tension generated by scleral fibroblasts was barely measurable. Notably, fibroblasts from the same organ differ significantly in their ability to generate tension. The authors also determined the intrinsic cellular tension of each fibroblast type, which was defined as the plateau tension divided by the mean cell volume. When comparing intrinsic tension with the ones measured during the experiment, the intrinsic cellular tension was at least of a similar order of magnitude. Cell size could therefore be an important factor influencing the homeostatic plateau level of tension. It is worth mentioning that Bisson et al. $(2004,2009)$ observed for Dupuytren's fibroblasts a significantly higher tension than for control fibroblasts but no plateau of tension. A likely explanation for the latter phenomenon is that for these cells the time to reach the homeostatic state was simply longer than the period for which the experiments were run. Another possible explanation would be the loss of the ability of these fibroblasts to control the mechanical state of their surrounding tissue. Interestingly, they also found that these cells reacted after the first of four consecutive uniaxial overloading events with a further increase in contraction, that is, not following the concept of homeostasis which would suggest a reduced contraction so that the gel tension returns toward the preferred 
plateau value. An uncontrolled contraction of fibroblasts in Dupuytren's tissue, regardless of the mechanical stimulus, could explain why patients stretching their fingers to overcome the disease particularly suffer from severe disease. Finally, Sawadkar et al. (2020) found that tendon fibroblasts produced lower tension with an increasing passage number.

Role of growth factors As reported by Brown et al. (2002), TGF- $\beta 1$ elevates both the rate and extent of cellular tension generation, although only up to a certain saturation value. TGF- $\beta 1$ increases cell tension and this may trigger integrin expression and contractile protein expression, and thereby enable higher tissue tension (Ignotz and Massague 1986; Brown et al. 2002). Note that Bisson et al. (2009) demonstrated that both the early contraction rate after $2 \mathrm{~h}$ and the rate after $20 \mathrm{~h}$ of Dupuytren's fibroblasts was significantly increased when stimulated with TGF- $\beta 1$. Notably, TGF- $\beta 1$ seems to affect also the cells' response to external mechanical loads. If a tissue equivalent in its homeostatic state is stretched, mechanical homeostasis typically ensures a subsequent decay of the tension back toward the homeostatic level, which naturally requires a decrease in the contractile activity of the cells in the tissue equivalent. However, when the TGF- $\beta 1$ treated cell-seeded gels were exposed in Bisson et al. (2009) to four consecutive uniaxial overloading events by rapidly increasing the length of the gel, a further increase was observed during the first three of these load steps. This suggests that the nodule and cord fibroblasts used in this experiment responded to the external stretch not by a decrease but rather by an increase of their contractile activity.

TGF- $\beta 1$ also appears to affect inelastic matrix remodeling. TGF- $\beta 1$ increases not only the overall tension generation by the cells, but also the mean RMT measurable after addition of Cytochalasin D (Marenzana et al. 2006). However, the ratio of RMT after addition of Cytochalasin D and the tension prior to the addition of Cytochalasin D was much smaller for TGF- $\beta 1$ treated cells compared to cultures without TGF- $\beta 1$, indicating that a lower percentage of tension is entrenched in the matrix.

Brown et al. (2002) also investigated effects of the concentration of fetal bovine serum (FBS) in the experimental culture medium. They found that in a medium with a concentration of $2 \%$, the tension rose more slowly and to a lower homeostatic value compared to a medium with a concentration of $10 \%$ FBS. The use of experimental medium without any FBS resulted in no tension generation. An increase in total tension generation for increasing concentrations of FBS was shown by Delvoye et al. (1991).

Cell-matrix interactions Cell-matrix interactions rely on the proper interplay of multiple components and substances. Kolodney and Wysolmerski (1992) studied the role of different parts of the cytoskeleton by treating the gels with drugs that selectively deactivated or disrupted particular constituents or interactions within the cytoskeleton. When Cytochalasin D—causing the disruption of actin filamentswas added to the culture medium after the plateau state had been reached, the entire tension disappeared rapidly for both chick embryo fibroblasts and human vein endothelial cells. These findings highlight that actin filaments are essential for mechanical homeostasis, both sensing and regulating the matrix. Conversely, treatment with the microtubule-disrupting drug nocodazole increased gel tension roughly by a factor of 2. Intact microtubules support cell shape and act against the tension of the actin cytoskeleton. Therefore, their disintegration may be expected to increase the contractile tension exerted by the cell on the surrounding tissue. Sethi et al. (2002) found on the basis of cell-populated glycosaminoglycan sponges that cells use their distinct receptor-ligand systems in a sequential order to exert tension on the surrounding matrix. Cells first attach through their fibronectin receptors, followed by their vitronectin receptors, and finally through their collagen receptors. It appears that if one of these stages is left out, cells can no longer generate the full tension through normal collagen attachment.

\subsection{Biaxially constrained tissue equivalents}

The inability of uniaxially constrained tissue equivalents to reproduce bi- or triaxial stress or strain states, which prevail in vivo, motivated the development of biaxial testing devices in the 2000s (Fig. 2d) (Knezevic et al. 2002; Thomopoulos et al. 2005, 2007; Humphrey et al. 2008; Sander et al. 2009; Hu et al. 2009, 2013; Lee et al. 2018; Eichinger et al. 2020). In many cases, however, biaxial settings have been used mainly for fairly general studies of fiber alignment and mechanical properties. Biaxial setups usually follow an approach very similar to the one of uniaxial ones. A premixed matrix solution containing a prescribed number of cells is cast into a biaxial mold (mostly square-shaped or cruciform-shaped (Fig. 2c)) and is then allowed to set for some time. Insets are used on four sides so that weights or motors can be connected to the gel to apply external loading, or to constrain the gel in two directions to study cellmediated compaction and the associated generation of tension. The following section briefly reviews key findings from biaxial experiments with tissue equivalents.

Fiber alignment One drawback of uniaxial collagen gels compared to biaxial gels is that, due to the experimental setup itself, a strong structural and therefore mechanical anisotropy arises. This anisotropy is characterized by an alignment of collagen fibers and therefore a stiffening in the constrained direction. Interestingly, it was shown that the intensity of the anisotropy induced this way by the boundary conditions was the same for tendon and cardiac fibroblasts (Thomopoulos et al. 2005). Conversely, fibers in cruciform-shaped biaxial gels were found to be 
randomly oriented in the central region, suggesting an isotropic response, whereas in the arms, uniaxial conditions induced a fiber alignment parallel to the axis of the arms (Hu et al. 2009). Also, the influence of external loading on fiber orientation was studied. If cruciform gels seeded with dermal fibroblasts were loaded in only one direction, fibers in the gel appeared to align in this direction also in the central region of the gel. If these gels were subsequently unloaded and then loaded orthogonally to the first loading direction, cells were found to remodel the fibers in the central region of the gel such that they first became randomly distributed again. After prolonged loading, finally, an anisotropic fiber alignment in the new loading direction was observed (Lee et al. 2008).

Mechanical properties The influence of static and cyclic equibiaxial stretching on the mechanical properties of fibroblast-seeded collagen gels has been studied over multiple days ( Chen et al. (2018)). Lee et al. (2018) observed that cyclic loading increased the stiffness more than static loading. Interestingly, the increased stiffness could be maintained even after cell lysis, again supporting the concept of inelastic cell-mediated matrix remodeling known already from uniaxial experiments (Marenzana et al. 2006). Based on second harmonic generation images, the enhancement of the mechanical properties was explained by thickening of collagen fibers in case of cyclic stretching (Lee et al. 2018).

Mechanical homeostasis in higher dimensions Regulation of matrix tension has only recently been studied in a fully controllable biaxial setup (Eichinger et al. 2020). In this study, NIH 3T3 fibroblasts were used (Fig 2c, d). Homeostatic tension in the biaxial setting was found to be higher and to be reached faster compared to a uniaxial setting (under otherwise identical conditions). Perturbations of the homeostatic state were studied under both equi-biaxial and strip-biaxial loading conditions. Notably, this was the first experiment to study relaxation after perturbation for up to $10 \mathrm{~h}$ (compared to less than $60 \mathrm{~min}$ in similar studies (Brown et al. 1998; Ezra et al. 2010)). This provided valuable information about whether the homeostatic state is fully or only partially restored after perturbations. When gels were released, gel tension was observed to increase above the prior level. By contrast, in case of a stretch perturbation, only a $\sim 5 \%$ offset was observed to remain compared to the prior tension. So far, it is not yet clear how these observations can be understood and to which extent they reflect general properties of mechanical homeostasis and tissue equivalents, e.g., considering that NIH 3T3 fibroblasts were used.

In an even more recent study, the mechanosensitive response of collagen gels seeded with primary aortic smooth muscle cells to a step-wise stretch was studied (Eichinger et al. 2021a). Both for release and extension by $1 \%$, which corresponded to a perturbation of $\sim 25 \%$ of the homeostatic state force, the gel tension returned toward the prior step within a tolerance of $\sim 10 \%$.

\section{Discussion and conclusion}

Studies with tissue equivalents have significantly increased our understanding of mechanobiology over the past few decades. Tissue equivalents represent controllable experimental model systems to study the evolution of biomechanical properties and mechanobiological responses of native tissues and tissue-engineered constructs with resident cells in a mechanically and chemically controlled three-dimensional matrix environment. Circular, cell-seeded free-floating collagen gels compact strongly over multiple days due to cell contraction (Simon et al. 2012, 2014). If similar gels are constrained in a uni- or biaxial setting at the boundaries and are therefore not able to deform the gel in the direction of loading, a two-stage response is generally observed: first, cells rapidly build up a certain level of tension (phase I), which is subsequently maintained (phase II) for a prolonged period (Brown et al. 1998; Jenkins et al. 1999; Brown et al. 2002; Sethi et al. 2002; Campbell et al. 2003; Marenzana et al. 2006; Karamichos et al. 2007; Dahlmann-Noor et al. 2007; Ezra et al. 2010; Courderot-masuyer 2017; Eichinger et al. 2020). The level of homeostatic tension appears to increase with both collagen concentration and cell density. By contrast, the rate of change leading to the homeostatic plateau tension seems to depend on the cell density but not on the collagen density. When the homeostatic state is perturbed mechanically, it appears that tissue equivalents work to re-establish the prior state within a particular range or tolerance. The exact response tends to depend, however, on the cell type and experimental conditions, including the presence of exogenous growth factors and ions that support different types of cellular activities, including matrix crosslinking (Brown et al. 1998; Ezra et al. 2010; Simon et al. 2014; Eichinger et al. 2020) (see Tables 1 and 2 for a collection of data from the literature and Fig. 4 for an overview).

Despite the impact of the aforementioned studies on our understanding of mechanobiology, many available experimental data are subject to at least one of the following three drawbacks (most drawbacks (i) and (ii)):

(i) Gels were subjected to uniaxial loading only, although most soft tissues are subjected to multiaxial mechanical states in vivo, with notable exceptions being tendons and some ligaments.

(ii) Relaxation intervals following external mechanical perturbations were often restricted to one hour or less, not allowing a definite answer within which tolerance the homeostatic state is restored after perturbations. 
Table 1 Overview of experimental methods and results related to uniaxially constrained tissue equivalents seeded with human dermal fibroblasts (FB)

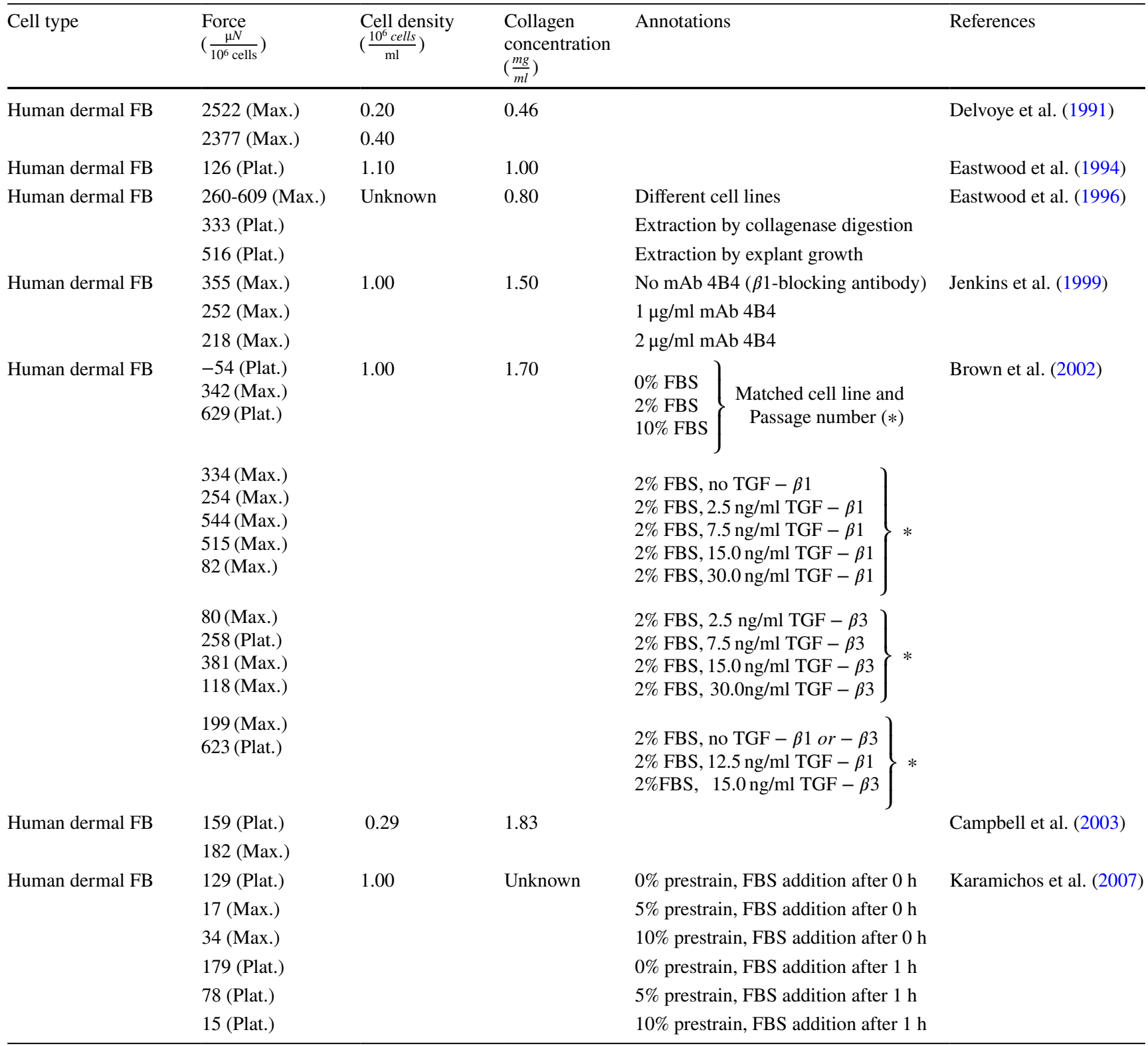

Forces refer to experiments without (or before) any external strain applied. The culture medium contained $10 \%$ FBS unless indicated differently. Maximal forces (Max.) and plateau forces (Plat.) are normalized by the number of cells used in the experiment. Due to missing data, the possibly more suitable normalization (force/cross-sectional area)/(number of cells/gel volume) was not possible. Therefore, information about the dimensions of the tissue equivalents (cross-sectional area, length, volume) in future studies would facilitate the comparison between experiments

(iii) Gels were seeded with cells from an immortalized line; thus, they are of little biological interest due to genetic and phenotypic changes resulting from multiple years of culture.

Besides these limitations, one must remember that in vivo conditions are necessarily much more complex than either in vitro or ex vivo conditions. Cells reside in vivo within a complex extracellular matrix consisting of myriad proteins, glycoproteins, and glycosaminoglycans, subject to complex aperiodic mechanical loading and influenced by paracrine signaling from multiple cell types, including inflammatory. Nevertheless, much has been learned and much can yet be learned with simple model systems. In the following, we summarize some of the most pressing remaining questions.

How does mechanical homeostasis arise? Probably the most important question yet to be answered is: which mechanosensitive mechanisms and processes at the level 
Table 2 Overview of experimental methods and results related to tissue equivalents seeded with cells other than human dermal fibroblasts (FB)

\begin{tabular}{|c|c|c|c|c|c|}
\hline Cell type & $\begin{array}{l}\text { Force } \\
\left(\frac{\mu \mathrm{N}}{10^{6} \text { cells }}\right)\end{array}$ & $\begin{array}{l}\text { Cell density } \\
\left(\frac{10^{6} \text { cells }}{m l}\right)\end{array}$ & $\begin{array}{l}\text { Collagen } \\
\text { concentra- } \\
\text { tion }\left(\frac{m g}{m l}\right)\end{array}$ & Annotations & References \\
\hline \multirow[t]{2}{*}{ Human osteosarcoma FB } & 221 (Max.) & 1.00 & 1.50 & Without $\alpha 2 \beta 2$ integrins & Jenkins et al. (1999) \\
\hline & 318 (Max.) & & & With $\alpha 2 \beta 2$ integrins & \\
\hline \multirow[t]{3}{*}{ Human ocular FB } & 18 (Plat.) & 7.00 & 1.50 & Human scleral FB & Dahlmann-Noor et al. (2007) \\
\hline & 208 (Plat.) & 1.00 & & FB human Tenon's & \\
\hline & 311 (Plat.) & 1.00 & & Human corneal FB & \\
\hline \multirow[t]{2}{*}{ Human tarsal plate FB } & 162 (Plat.) & 1.00 & 1.58 & Healthy upper eyelid FB & Ezra et al. (2010) \\
\hline & 437 (Plat.) & & & Floppy eyelid syndrome FB & \\
\hline \multirow[t]{3}{*}{ Human fascial tissue FB } & 80 (Max.) & 1.00 & 1.88 & Healthy carpal ligament (HCL) & Bisson et al. (2004) \\
\hline & 219 (Max.) & & & Dupuytren's cord (DC) & \\
\hline & 290 (Max.) & & & Dupuytren's nodule (DN) & \\
\hline \multirow[t]{6}{*}{ Human fascial tissue FB } & 91 (Max.) & 1.00 & 1.88 & HCL FB, without TGF- $\beta 1$ & Bisson et al. (2009) \\
\hline & 234 (Max.) & & & DC FB, without TGF- $\beta 1$ & \\
\hline & 262 (Max.) & & & DN FB, without TGF- $\beta 1$ & \\
\hline & 330 (Max.) & & & HCL FB, 2 ng/ml TGF- $\beta 1$ & \\
\hline & 428 (Max.) & & & DC FB, 2 ng/ml TGF- $\beta 1$ & \\
\hline & 560 (Max.) & & & DN FB, 2 ng/ml TGF- $\beta 1$ & \\
\hline Calf dermal FB & 5623 (Plat.) & 0.20 & 0.46 & & Delvoye et al. (1991) \\
\hline Chick embryo FB & 585 (Plat.) & 0.77 & 0.87 & & $\begin{array}{l}\text { Kolodney and Wysolmerski } \\
\text { (1992) }\end{array}$ \\
\hline \multirow[t]{2}{*}{ Rabbit tendon FB } & 124 (Max.) & Unknown & 0.80 & Endotenon FB & Eastwood et al. (1996) \\
\hline & 172 (Max.) & & & Sheath FB & \\
\hline \multirow[t]{4}{*}{ Rabbit tendon FB } & 168 (Plat.) & 1.00 & Unknown & $\mathrm{P} 0, \mathrm{P}=$ passage number & Sawadkar et al. (2020) \\
\hline & 126 (Max.) & & & $\mathrm{P} 1$ & \\
\hline & 90 (Max.) & & & P3 & \\
\hline & 51 (Max.) & & & P6 & \\
\hline \multirow[t]{4}{*}{ Rat tendon FB } & 197 (Max.) & 1.00 & 1.70 & Without TGF- $\beta 1$ & Marenzana et al. (2006) \\
\hline & & & & $\mathrm{RMT}=53 \mu \mathrm{N} / 10^{6}$ cells & \\
\hline & 456 (Max.) & & & $15.0 \mathrm{ng} / \mathrm{ml}$ TGF- $\beta 1$ & \\
\hline & & & & $\mathrm{RMT}=40 \mu \mathrm{N} / 10^{6}$ cells & \\
\hline \multirow[t]{7}{*}{ NIH 3T3 FB } & 255(Plat.) & 0.20 & 1.50 & Uniaxially constrained & Eichinger et al. (2020) \\
\hline & 213 (Plat.) & 0.50 & 2.50 & Uniaxially constrained & \\
\hline & 187 (Plat.) & 0.50 & 1.50 & Uniaxially constrained & \\
\hline & 135 (Plat.) & 0.50 & 0.80 & Uniaxially constrained & \\
\hline & 128 (Plat.) & 1.00 & 1.50 & Uniaxially constrained & \\
\hline & 138 (Plat.) & 1.00 & 1.50 & $\begin{array}{l}\text { Biaxially constrained } \mathrm{x} \text {-direc- } \\
\text { tion }\end{array}$ & \\
\hline & 142 (Plat.) & & & $\begin{array}{l}\text { Biaxially constrained y-direc- } \\
\text { tion }\end{array}$ & \\
\hline \multirow{4}{*}{$\begin{array}{l}\text { Porcine pulmonary arte- } \\
\text { rial smooth muscle cell }\end{array}$} & 759 (Plat.) & 1.00 & 1.00 & Inner $25 \%$ of artery, healthy & Hall et al. (2007) \\
\hline & 1119 (Plat.) & & & Outer $50 \%$ of artery, healthy & \\
\hline & 524 (Plat.) & & & Inner $25 \%$ of artery, hypoxic & \\
\hline & 228 (Plat.) & & & Outer $50 \%$ of artery, hypoxic & \\
\hline
\end{tabular}

Experiments were conducted in a uniaxial setup with medium containing 10\% FBS unless indicated differently. Forces refer to experiments without (or before) any external strain applied. The RMT was obtained $12 \mathrm{~h}$ after addition of the actin cytoskeleton disrupting agent cytochalasin D after $24 \mathrm{~h}$ in culture. Maximal forces (Max.) and plateau forces (Plat.) are normalized by the number of cells used in the experiment. Analogously to the studies with dermal fibroblast, the possibly more suitable normalization (force/cross-sectional area)/(number of cells/gel volume) was not possible due to a lack of data, again suggesting a need to provide information about the cross-sectional area in future studies 


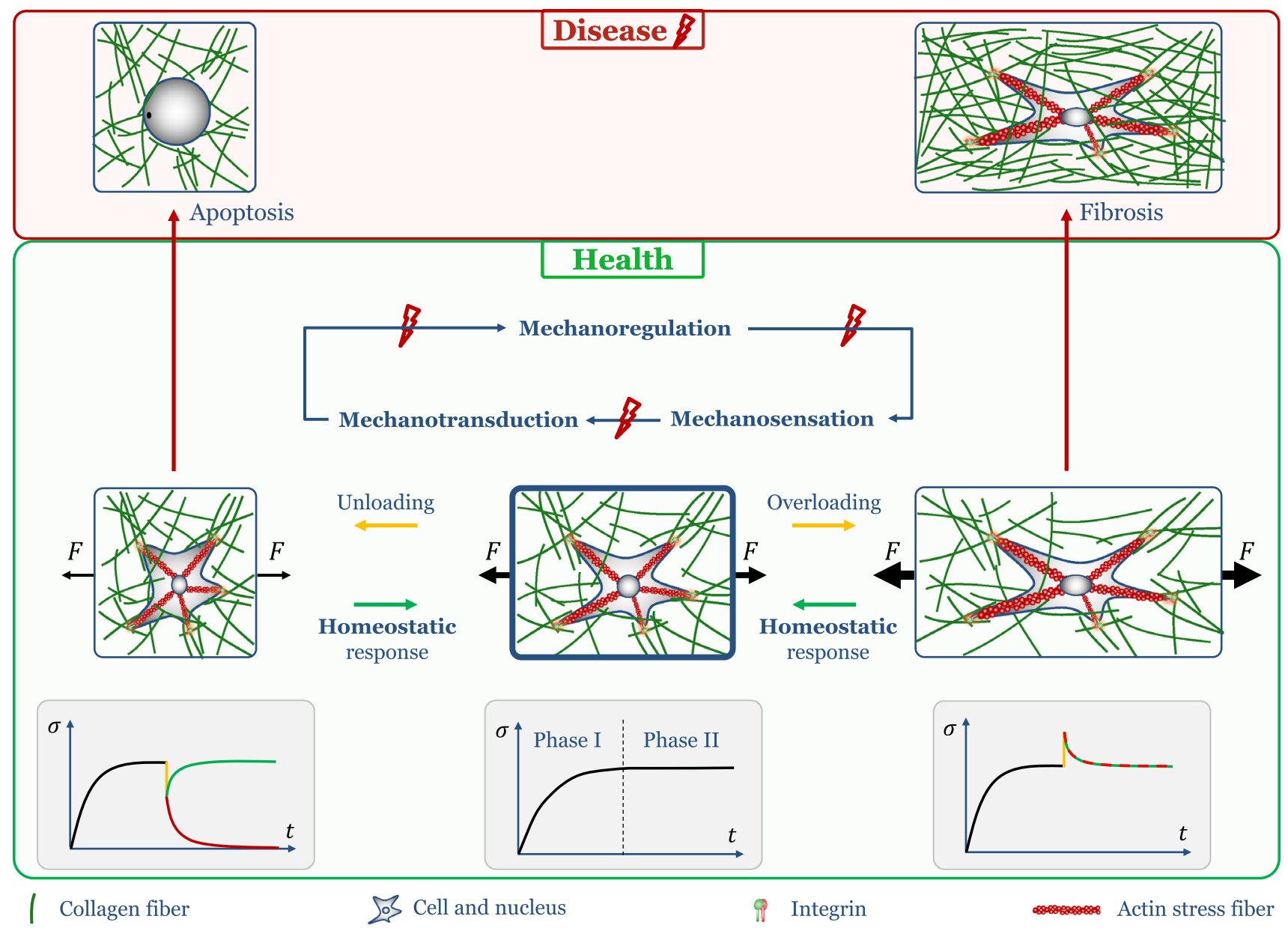

Fig. 4 Schematic drawing of cell-matrix interactions in health and disease. Center: cell in normal conditions interacting via integrins with surrounding ECM, which in vivo typically exhibits some tension. Bottom row shows typical behavior of tissue equivalents developing a homeostatic nonzero plateau of tension over time. Right: In case of further increases in tension, i.e., overloading, healthy tissue seeks to restore the prior mechanical state due to a homeostatic feedback loop consisting of mechanosensation, mechanotransduction, and mechanoregulation. If this feedback loop is compromised, pathologi- cal signaling can lead to a fibrotic response (top right). In general, both the healthy and the fibrotic reaction may help to restore the preferred mechanical state (bottom right). Left: in case of decreases in tension, i.e., under-loading, e.g., due to injury, homeostatic feedback loops can lead to re-establishment of a homeostatic state. By contrast, pathological mechanosensitivity of tissues can lead to apoptosis (top row). The homeostatic feedback loop aims at restoring the homeostatic state, whereas apoptosis may lead to tissue failure (bottom row)

strain are effectively regulated. The micro-biomechanical and biochemical mechanisms of cellular mechano-sensing, transduction of cues into cellular regulative reactions via intracellular signaling pathways, and the controlled production, prestressing and degradation of extracellular matrix remain poorly understood. Tissue culture experiments are simple systems where accurately controlled stress and strain states can be imposed to study cellular responses. Especially interesting would be the use of cells with induced defects to study exact roles of specific components of the intracellular control system that gives rise to mechanical homeostasis. Similarly, cell treatment with drugs that just target one specific mechanism could provide important insights. 
Which regulatory processes govern mechanical homeostasis on short and long time scales? In addition to different spatial scales, different time scales also need to be considered. Mechanical homeostasis is closely related to growth and remodeling. The latter refers to the inelastic reorganization of the microstructure of tissues, whereas growth describes the process of production and removal of tissue mass. This implies that mechanical homeostasis probably involves at least two very different biophysical processes, which can be expected to evolve in general at different time scales. Remodeling appears to regulate the mechanical state on the time scale of hours to days. Structurally significant mass turnover, that is, production and removal of tissue mass, most likely evolves over days to weeks (Nakagawa et al. 1989; Matsumoto and Hayashi 1994), and over such prolonged periods, mechanical homeostasis has not yet been studied using tissue equivalents given the challenges with long-term culture.

What is the target of mechanical homeostasis? So far, it remains controversial which mechanical quantity might be the target of mechanical homeostasis. There is evidence that it may be closely linked to tension in particular tissues because a wide range of different animal species, differing in size and body weight over multiple orders of magnitude, develop nearly the same tension per medial lamellar unit (or wall stress) in the aorta (Wolinsky and Glagov 1967). Indeed, externally perturbed tissue equivalents appear to restore their tension toward the level prior to the perturbation (Delvoye et al. 1991; Brown et al. 1998; Ezra et al. 2010). Yet, other equally striking studies report that wall stiffness at mean blood pressure also tends to be nearly the same in the aorta across various invertebrates and vertebrates (Shadwick 1999). Könnig et al. (2018) yet reported that fibroblast-populated biomaterial scaffolds reacted differently when subjected to environments with different stiffnesses. In a 2-week period, compaction was significantly less and tension higher with stiffer surroundings. Other recent investigations suggest loading rate as a crucial parameter for mechanobiological homeostasis on the cellular scale (Zhu et al. 2016; EloseguiArtola et al. 2018). This leaves open the key question which target quantity is governing mechanical homeostasis at the tissue and organ level: is it strain, tension/stress, stiffness, stress or strain rate, or some other more complex quantity? To answer this and other related questions, it could, for example, be helpful to develop tissue culture experiments where such quantities can be controlled independently for prolonged periods.

What is the homeostatic range and when does homeostasis become adaptive? Most in vitro studies of mechanical homeostasis in tissue equivalents are restricted to periods within which it is often hard to decide at which tolerance mechanical homeostasis aims to restore a certain target state. Moreover, it still remains unclear how and when the homeostatic target value or the tolerance around it change, following the concept of adaptive homeostasis (Davies 2016).

What does mechanical homeostasis mean in higher dimensions? In vivo observations so far focused on the component of tension in the circumferential direction of blood vessels (Wolinsky and Glagov 1967; Shadwick 1999), not allowing a generalization of the concept of mechanobiological homeostasis to higher dimensions. Similarly, in tissue cultures, quantitative studies of the homeostatic plateau tension have been performed almost exclusively in uniaxial settings. This is a major concern noting that in vivo, living tissues are predominantly subjected to complex multiaxial loading. To close the resulting gap in our understanding of mechanical homeostasis, there is a pressing need for more studies in multiaxial settings, with coordinate invariant mechanical metrics important to consider (e.g., although stress may be uniaxial with respect to the long-axis of a uniaxially loaded sample, shear stress yet exists relative to other coordinate systems, hence even in simple cases, we do not really know what component or collection of components of stress the cells may respond to). Additional studies and concepts will be needed to answer the question what mechanical homeostasis exactly means in higher dimensions.

What are the different targets of different cell types and what is the influence of tissue origin? So far, limited knowledge is available on how cell type and tissue origin influence mechanical homeostasis in tissue equivalents. In vivo, cells from different tissues have been exposed to different loading and different environments, which in general can be expected to affect cell function (Sewanan et al. 2019). A key question in this regard is how and for how long do cells remember their specific prior function when transferred to an artificial environment in vitro. Moreover, given that a basic tenet of experimentation is to keep everything the same except the one variable of interest, the question is how to quantify and assess the prior function and environment of cells used in tissue culture experiments. Alternatively, one may think about more complex ex vivo experimental devices and strategies, but matrix complexity remains complicated. In this regard, using matrices from decellularized tissues (as in tissue engineering) needs further attention.

As mentioned before, a major limitation of many available studies is the use of immortalized cell lines, or the frequent use of fibroblasts in cases of primary cells. The extension of these studies to other differentiated cells, stem cells (Butler et al. 2010; Leong et al. 2010), and cells stemming from diseased, for example, fibrotic or aneurysmal tissues, with possible defects that may, for example, affect cell-matrix interactions, will be helpful to further understand mechanical homeostasis in health and disease.

Importantly, to allow better comparisons across studies, more consistent experimental guidelines should be adopted. 
Such is difficult, however, given the many different methods, cell types, tissue types, species, ages, disease conditions, and so forth. At the minimum, there is a need for more precise reporting. It may be reported that vascular smooth muscle cells were harvested from the aorta, for example, yet these cells arise from different embryonic origins when contrasting the aortic root, ascending aorta, and abdominal aorta. Site-specific differences may be critical determinants of findings in culture. One can also read that dermal fibroblasts were used; from where on the body were these cells taken, however, and what was the age and sex of the donor are often undocumented pieces of information that may be critical in comparing results. For example, it was even shown that human ocular fibroblasts from different regions of the eye produce significantly different tension (DahlmannNoor et al. 2007). Of course, precise information on culture medium and gel constituents or gel preparation time should be given since they influence the behavior of cells with respect to mechanical homeostasis. Similarly, also cell passage number (Sawadkar et al. 2020) and isolation process (Eastwood et al. 1996) have a major impact. Finally, normalization of the measured data could prove useful, as, for example, a normalized force $F_{n}$,

$F_{n}=\frac{\text { force/cross-sectional area }}{\text { number of cells/gel volume }}$,

would allow a better comparison between different studies, although information about the dimensions of the tissue equivalents (cross-sectional area, length, volume) remains indispensable. By including this information in future reports, it may be possible to develop dimensionless quantities characterizing the mechanobiological properties of tissue equivalents, following the example of fluid mechanics where dimensionless quantities such as the Reynolds or Stokes number have greatly contributed to our understanding of complex physical systems.

Summing up, experiments with tissue equivalents have contributed significantly to our understanding of mechanobiology. Nevertheless, many key questions have not yet been addressed, or at least not fully. Mathematical modeling of mechanobiology is a fast growing field and could help tremendously in understanding the foundations of mechanical homeostasis (Holzapfel et al. 2000; Wakatsuki et al. 2000; Humphrey and Rajagopal 2002; Watton et al. 2004; Marquez et al. 2005; Mauri et al. 2016; Loerakker et al. 2016; Cyron et al. 2016; Braeu et al. 2017; Ban et al. 2019; Domaschke et al. 2019; Eichinger et al. 2021a, b). To support mathematical modeling, it will be particularly important to collect larger sets of reliable quantitative experimental data, especially about bi- or triaxial mechanical states. Understanding the exact mechanisms by which cells sense and regulate their mechanical microenvironment and how these mechanisms macroscopically affect tissues will be key for the development of therapies against numerous diseases such as aneurysms or cancer. Moreover, it will be of great importance for future regenerative medicine in general.

Supplementary Information The online version contains supplementary material available at https://doi.org/10.1007/s10237-021-01433-9.

Acknowledgements We thank Dr. Jason Szafron, Ms. Isabella Jennings, and Ms. Lydia Ehmer for technical assistance and thoughtful discussions.

Funding Open Access funding enabled and organized by Projekt DEAL. Funded by the Deutsche Forschungsgemeinschaft (DFG, German Research Foundation)-Projektnummer 257981274, Projektnummer 386349077 . The authors also gratefully acknowledge financial support by the International Graduate School of Science and Engineering (IGSSE) of Technical University of Munich, Germany.

\section{Compliance with ethical standards}

Conflicts of interest The authors declare that they have no conflict of interests.

Open Access This article is licensed under a Creative Commons Attribution 4.0 International License, which permits use, sharing, adaptation, distribution and reproduction in any medium or format, as long as you give appropriate credit to the original author(s) and the source, provide a link to the Creative Commons licence, and indicate if changes were made. The images or other third party material in this article are included in the article's Creative Commons licence, unless indicated otherwise in a credit line to the material. If material is not included in the article's Creative Commons licence and your intended use is not permitted by statutory regulation or exceeds the permitted use, you will need to obtain permission directly from the copyright holder. To view a copy of this licence, visit http://creativecommons.org/licenses/by/4.0/.

\section{References}

Alcaraz J, Mori H, Ghajar CM, Brownfield D, Galgoczy R, Bissell MJ (2011) Collective epithelial cell invasion overcomes mechanical barriers of collagenous extracellular matrix by a narrow tube-like geometry and MMP14-dependent local softening. Integr Biol 3(12):1153-1166

Baker BM, Chen CS (2012) Deconstructing the third dimension-how 3D culture microenvironments alter cellular cues. J Cell Sci 125(13):3015-3024

Ban E, Wang H, Franklin JM, Liphardt JT, Janmey PA, Shenoy VB (2019) Strong triaxial coupling and anomalous Poisson effect in collagen networks. In: Proceedings of the National Academy of Sciences of the United States of America, pp 201815659

Bangasser BL, Shamsan GA, Chan CE, Opoku KN, Tuezel E, Schlichtmann BW, Kasim JA, Fuller BJ, McCullough BR, Rosenfeld SS, Odde DJ (2017) Shifting the optimal stiffness for cell migration. Nat Commun 8(1):1-10

Barocas VH, Girton TS, Tranquillo RT (1998) Engineered alignment in media equivalents: magnetic preaiignment and mandrel compaction. J Biomech Eng 120(5):660-666

Bates RC, Lincz LF, Burns GF (1995) Involvement of integrins in cell survival. Cancer Metastasis Rev 14(3):191-203 
Bell E, Ivarsson B, Merrill C (1979) Production of a tissue-like structure by contraction of collagen lattices by human fibroblasts of different proliferative potential in vitro. Proc Natl Acad Sci U S A 76(3):1274-8

Bernard C (1865) An introduction to the study of experimental medicine. Dover Pubn Inc, New York

Bhole AP, Flynn BP, Liles M, Saeidi N, Dimarzio CA, Ruberti JW (2009) Mechanical strain enhances survivability of collagen micronetworks in the presence of collagenase: implications for load-bearing matrix growth and stability. Philos Trans R Soc A Math Phys Eng Sci 367(1902):3339-3362

Bissel MJ, Aggeler J (1987) Dynamic reciprocity: How do extracellular matrix and hormones direct gene expression? Prog Clin Biol Res 249:251-262

Bisson MA, Beckett KS, McGrouther DA, Grobbelaar AO, Mudera V (2009) Transforming growth factor- $\beta 1$ stimulation enhances Dupuytren's fibroblast contraction in response to uniaxial mechanical load within a 3-dimensional collagen gel. J Hand Surg Am 34(6):1102-1110

Bisson MA, Mudera V, McGrouther DA, Grobbelaar AO (2004) The contractile properties and responses to tensional loading of Dupuytren's disease-derived fibroblasts are altered: A cause of the contracture? Plast Reconstr Surg 113(2):611-621

Boettiger D, Hammer DA, Rozenberg GI, Johnson KR, Margulies SS, Weaver VM, Dembo M, Reinhart-King CA, Gefen A, Lakins JN, Zahir N, Paszek MJ (2005) Tensional homeostasis and the malignant phenotype. Cancer Cell 8(3):241-254

Bonnans C, Chou J, Werb Z (2014) Remodelling the extracellular matrix in development and disease. Nat Rev Mol Cell Biol 15(12):786-801

Bonnier F, Keating ME, Wróbel TP, Majzner K, Baranska M, GarciaMunoz A, Blanco A, Byrne HJ (2015) Cell viability assessment using the Alamar blue assay: A comparison of 2D and 3D cell culture models. Toxicol Vitr 29(1):124-131

Braeu FA, Seitz A, Aydin RC, Cyron CJ (2017) Homogenized constrained mixture models for anisotropic volumetric growth and remodeling. Biomech Model Mechanobiol 16(3):889-906

Brown RA, Prajapati R, McGrouther DA, Yannas IV, Eastwood M (1998) Tensional homeostasis in dermal fibroblasts: Mechanical responses to mechanical loading in three-dimensional substrates. J Cell Physiol 175(3):323-332

Brown RA, Sethi KK, Gwanmesia I, Raemdonck D, Eastwood M, Mudera V (2002) Enhanced fibroblast contraction of 3D collagen lattices and integrin expression by TGF- $\beta 1$ and $-\beta 3$ : Mechanoregulatory growth factors? Exp Cell Res 274(2):310-322

Butcher DT, Alliston T, Weaver VM (2009) A tense situation: forcing tumour progression. Nat Rev Cancer 9(2):108-122

Butler DL, Gooch C, Kinneberg KR, Boivin GP, Galloway MT, Nirmalanandhan VS, Shearn JT, Dyment NA, Juncosa-Melvin N (2010) The use of mesenchymal stem cells in collagen-based scaffolds for tissue-engineered repair of tendons. Nat Protoc 5(5):849-863

Buttle DJ, Ehrlich HP (1983) Comparative studies of collagen lattice contraction utilizing a normal and a transformed cell line. J Cell Physiol 116(2):159-166

Califano JP, Reinhart-King CA (2010) Substrate stiffness and cell area predict cellular traction stresses in single cells and cells in contact. Cell Mol Bioeng 3(1):68-75

Campbell BH, Clark WW, Wang JHC (2003) A multi-station culture force monitor system to study cellular contractility. J Biomech 36(1):137-140

Cannon WB (1929) Reviews 1929. Physiol Rev 9(3):399-431

Cannon WB (1932) The Wisdom of the Body. W.W Norton, Incorporated, New York

Cavalcanti-Adam EA, Micoulet A, Volberg T, Geiger B, Spatz JP, Kessler H (2007) Cell spreading and focal adhesion dynamics are regulated by spacing of integrin ligands. Biophys J 92(8):2964-2974

Chan CE, Odde DJ (2008) Traction dynamics of filopodia on compliant substrates. Science (80-) 322(5908):1687-1691

Chen K, Vigliotti A, Bacca M, McMeeking RM, Deshpande VS, Holmes JW (2018) Role of boundary conditions in determining cell alignment in response to stretch. Proc Natl Acad Sci U S A 115(5):986-991

Cheng Q, Sun Z, Meininger G, Almasri M (2013) PDMS elastic micropost arrays for studying vascular smooth muscle cells. Sensors Actuators B Chem 188:1055-1063

Chiquet M, Gelman L, Lutz R, Maier S (2009) From mechanotransduction to extracellular matrix gene expression in fibroblasts. Biochim Biophys Acta Mol Cell Res 1793(5):911-920

Chovatiya R, Medzhitov R (2014) Stress, inflammation, and defense of homeostasis. Mol Cell 54(2):281-288

Courderot-masuyer C (2017) Mechanical Properties of Fibroblasts. Agache's Meas. Ski

Cox TR, Erler JT (2011) Remodeling and homeostasis of the extracellular matrix: implications for fibrotic diseases and cancer. Dis Model Mech 4(2):165-178

Cyron CJ, Aydin RC, Humphrey JD (2016) A homogenized constrained mixture (and mechanical analog) model for growth and remodeling of soft tissue. Biomech Model Mechanobiol 15(6):1389-1403

Cyron CJ, Humphrey JD (2014) Vascular homeostasis and the concept of mechanobiological stability. Int J Eng Sci 85:203-223

Cyron CJ, Humphrey JD (2017) Growth and remodeling of load-bearing biological soft tissues. Meccanica 52(3):645-664

Cyron CJ, Wilson JS, Humphrey JD (2014) Mechanobiological stability: A new paradigm to understand the enlargement of aneurysms? J R Soc Interface 11(100):20140680

Dahlmann-Noor AH, Martin-Martin B, Eastwood M, Khaw PT, Bailly M (2007) Dynamic protrusive cell behaviour generates force and drives early matrix contraction by fibroblasts. Exp Cell Res 313(20):4158-4169

Dallon JC, Ehrlich HP (2008) A review of fibroblast-populated collagen lattices. Wound Repair Regen 16(4):472-479

Davies KJA (2016) Adaptive homeostasis. Mol Aspects Med 49:1-7

Davis H (1867) Conservative surgery. Appleton \& Co., New York

Delvoye P, Wiliquet P, Levêque J-L, Nusgens BV, Lapière CM (1991) Measurement of mechanical forces generated by skin fibroblasts embedded in a three-dimensional collagen gel. J Invest Dermatol 97(5):898-902

Domaschke S, Morel A, Fortunato G, Ehret AE (2019) Random auxetics from buckling fibre networks. Nat Commun 10(1):1-8

Duval K, Grover H, Han LH, Mou Y, Pegoraro AF, Fredberg J, Chen Z (2017) Modeling physiological events in 2D vs 3D cell culture. Physiology 32(4):266-277

Eastwood M, McGrouther DA, Brown RA (1994) A culture force monitor for measurement of contraction forces generated in human dermal fibroblast cultures: evidence for cell-matrix mechanical signalling. BBA - Gen Subj 1201(2):186-192

Eastwood M, Porter R, Khan U, McGrouther G, Brown R (1996) Quantitative analysis of collagen gel contractile forces generated by dermal fibroblasts and the relationship to cell morphology. J Cell Physiol 166(1):33-42

Ehrlich HP, Griswold TR, Rajaratnam JB (1986) Studies on vascular smooth muscle cells and dermal fibroblasts in collagen matrices. Effects Heparin Exp Cell Res 164(1):154-162

Ehrlich HP, Rittenberg T (2000) Differences in the mechanism for high-versus moderate-density fibroblast-populated collagen lattice contraction. J Cell Physiol 185(February):432-439

Eichinger JF, Aydin RC, Wall WA, Humphrey JD, Cyron CJ (2021a) What do cells regulate in soft tissues on short time scales? to be submitted 
Eichinger JF, Grill MJ, Aydin RC, Wall WA, Humphrey JD, Cyron CJ (2021b) A computational framework for modeling cell-matrix interactions in soft biological tissues. to be submitted

Eichinger JF, Paukner D, Szafron JM, Aydin RC, Humphrey JD, Cyron CJ (2020) Computer-controlled biaxial bioreactor for investigating cell-mediated homeostasis in tissue equivalents. J Biomech Eng 142(c):1-22

Elosegui-Artola A, Trepat X, Roca-Cusachs P (2018) Control of mechanotransduction by molecular clutch dynamics. Trends Cell Biol 28(5):356-367

Ezra DG, Ellis JS, Beaconsfield M, Collin R, Bailly M (2010) Changes in fibroblast mechanostat set point and mechanosensitivity: an adaptive response to mechanical stress in floppy eyelid syndrome. Investig Ophthalmol Vis Sci 51(8):3853-3863

Flynn BP, Bhole AP, Saeidi N, Liles M, Dimarzio CA, Ruberti JW (2010) Mechanical strain stabilizes reconstituted collagen fibrils against enzymatic degradation by mammalian collagenase matrix metalloproteinase 8 (MMP-8). PLoS ONE 5(8):21-23

Friedl P, Sahai E, Weiss S, Yamada KM (2012) New dimensions in cell migration. Nat Rev Mol Cell Biol 13(11):743-747

Ghibaudo M, Saez A, Trichet L, Xayaphoummine A, Browaeys J, Silberzan P, Buguin A, Ladoux B (2008) Traction forces and rigidity sensing regulate cell functions. Soft Matter 4(9):1836-1843

Grenier G, Rémy-Zolghadri M, Larouche D, Gauvin R, Baker K, Bergeron F, Dupuis D, Langelier E, Rancourt D, Auger FA, Germain L (2005) Tissue reorganization in response to mechanical load increases functionality. Tissue Eng 11(1-2):90-100

Grinnell F (2000) Fibroblast-collagen-matrix contraction: growthfactor signalling and mechanical loading. Trends Cell Biol 10(9):362-365

Grinnell $\mathrm{F}$, Ho CH (2002) Transforming growth factor $\beta$ stimulates fibroblast-collagen matrix contraction by different mechanisms in mechanically loaded and unloaded matrices. Exp Cell Res 273(2):248-255

Grinnell F, Lamke CR (1984) Reorganization of hydrated collagen lattices by human skin fibroblasts. J Cell Sci 66:51-63

Grinnell F, Petroll WM (2010) Cell Motility and Mechanics in ThreeDimensional Collagen Matrices. Annu Rev Cell Dev Biol 26(1):335-361

Hall MS, Alisafaei F, Ban E, Feng X, Hui C-Y, Shenoy VB, Wu M (2016) Fibrous nonlinear elasticity enables positive mechanical feedback between cells and ECMs. Proc Natl Acad Sci 113(49):14043-14048

Hall SM, Soueid A, Smith T, Brown RA, Haworth SG, Mudera V (2007) Spatial differences of cellular origins and in vivo hypoxia modify contractile properties of pulmonary artery smooth muscle cells: lessons for arterial tissue engineering S. J Tissue Eng Regen Med 1:287-295

Holzapfel GA, Gasser TC, Ogden RW (2000) A new constitutive framework for arterial wall mechanics and a comparative study of material models. J Elast 61(1-3):1-48

Hu J-J, Humphrey JD, Yeh AT (2009) Characterization of engineered tissue development under biaxial stretch using nonlinear optical microscopy. Tissue Eng Part A 15(7):1553-1564

Hu JJ, Liu YC, Chen GW, Wang MX, Lee PY (2013) Development of fibroblast-seeded collagen gels under planar biaxial mechanical constraints: A biomechanical study. Biomech Model Mechanobiol 12(5):849-868

Humphrey JD (2001) Stress, strain, and mechanotransduction in cells. J Biomech Eng 123(6):638-641

Humphrey JD, Dufresne ER, Schwartz MA (2014a) Mechanotransduction and extracellular matrix homeostasis. Nat Rev Mol Cell Biol 15(12):802-812

Humphrey JD, Milewicz DM, Tellides G, Schwartz MA (2014b) Dysfunctional mechanosensing in aneurysms. Science 344(6183):477-479
Humphrey JD, Rajagopal KR (2002) A constrained mixture model for growth and remodeling of soft tissues. Math Model Methods Appl Sci 12(3):407-430

Humphrey JD, Wells PB, Baek S, Hu J-J, McLeroy K, Yeh AT (2008) A theoretically-motivated biaxial tissue culture system with intravital microscopy. Biomech Model Mechanobiol 7(4):323-34

Ignotz RA, Massague J (1986) Transforming growth factor- $\beta$ stimulates the expression of fibronectin and collagen and their incorporation into the extracellular matrix. J Biol Chem 261(9):4337-4345

Isenberg BC, Williams C, Tranquillo RT (2006) Small-diameter artificial arteries engineered in vitro. Circ Res 98(1):25-35

Jenkins G, Redwood KL, Meadows L, Green MR (1999) Effect of gel re-organization and tensional forces on alpha2beta1 integrin levels in dermal fibroblasts. Eur J Biochem 263(1):93-103

Jiang G, Huang AH, Cai Y, Tanase M, Sheetz MP (2006) Rigidity sensing at the leading edge through \textalpha $\mathrm{v} \backslash$ textbeta 3 integrins and RPTP \textalpha. Biophys J 90(5):1804-1809

Jin T, Li L, Siow RCMM, Liu K-KK (2015) A novel collagen gel-based measurement technique for quantitation of cell contraction force. J R Soc Interface 12(106):20141365

Joshi J, Mahajan G, Kothapalli CR (2018) Three-dimensional collagenous niche and azacytidine selectively promote time-dependent cardiomyogenesis from human bone marrow-derived MSC spheroids. Biotechnol Bioeng 115(8):2013-2026

Karamichos D, Brown RA, Mudera V (2007) Collagen stiffness regulates cellular contraction and matrix remodeling gene expression. J Biomed Mater Res, Part A 83A(3):887-894

Kelynack KJ, Hewitson TD, Nicholls KM, Darby I, Becker GJ (2000) Nephrology dialysis transplantation human renal fibroblast contraction of collagen I lattices is an integrin- mediated process. Nephrol Dial Transplanat 15:1766-1772

Kim J, Zheng Y, Alobaidi AA, Nan H, Tian J, Jiao Y, Sun B (2019) Collective ECM remodeling organizes 3D collective cancer invasion. pp 1-6

Knezevic V, Sim AJ, Borg TK, Holmes JW (2002) Isotonic biaxial loading of fibroblast-populated collagen gels: a versatile, lowcost system for the study of mechanobiology. Biomech Model Mechanobiol 1(1):59-67

Kolodney MS, Wysolmerski RB (1992) Isometric contraction by fibroblasts and endothelial cells in tissue culture?: A quantitative study. J Cell Biol 117(1):73-82

Könnig D, Herrera A, Duda GN, Petersen A (2018) Mechanosensation across borders: fibroblasts inside a macroporous scaffold sense and respond to the mechanical environment beyond the scaffold walls. J Tissue Eng Regen Med 12(1):265-275

Kotas ME, Medzhitov R (2015) Homeostasis, inflammation, and disease susceptibility. Cell 160(5):816-827

Kural MH, Billiar KL (2016) Myofibroblast persistence with real-time changes in boundary stiffness. Acta Biomater 32:223-230

Lee EJ, Holmes JW, Costa KD (2008) Remodeling of engineered tissue anisotropy in response to altered loading conditions. Ann Biomed Eng 36(8):1322-1334

Lee PY, Liu YC, Wang MX, Hu JJ (2018) Fibroblast-seeded collagen gels in response to dynamic equibiaxial mechanical stimuli: a biomechanical study. J Biomech 78:134-142

Legant WR, Pathak A, Yang MT, Deshpande VS, McMeeking RM, Chen CS (2009) Microfabricated tissue gauges to measure and manipulate forces from 3D microtissues. Proc Natl Acad Sci U S A 106(25):10097-10102

Leong WS, Tay CY, Yu H, Li A, Wu SC, Duc DH, Lim CT, Tan LP (2010) Thickness sensing of hMSCs on collagen gel directs stem cell fate. Biochem Biophys Res Commun 401(2):287-292

Lerche M, Elosegui-Artola A, Guzmán C, Georgiadou M, Kechagia JZ, Gulberg D, Roca-Cusachs P, Peuhu E, Ivaska J (2019) Integrin binding dynamics modulate ligand-specific mechanosensing in mammary gland fibroblasts. bioRxiv, pages $1-27$ 
Loerakker S, Ristori T, Baaijens FP (2016) A computational analysis of cell-mediated compaction and collagen remodeling in tissue-engineered heart valves. J Mech Behav Biomed Mater 58:173-187

Lu P, Takai K, Weaver VM, Werb Z (2011) Extracellular Matrix degradation and remodeling in development and disease. Cold Spring Harb Perspect Biol 3(12):1-24

Lu P, Weaver VM, Werb Z (2012) The extracellular matrix: a dynamic niche in cancer progression. J Cell Biol 196(4):395-406

Mammoto A, Mammoto T, Ingber DE (2012) Mechanosensitive mechanisms in transcriptional regulation. J Cell Sci 125(13):3061-3073

Marenzana M, Wilson-Jones N, Mudera V, Brown RA (2006) The origins and regulation of tissue tension: identification of collagen tension-fixation process in vitro. Exp Cell Res 312(4):423-433

Marquez JP, Genin GM, Zahalak GI, Elson EL (2005) Thin bio-artificial tissues in plane stress: the relationship between cell and tissue strain, and an improved constitutive model. Biophys $\mathbf{J}$ 88(2):765-777

Matsumoto T, Hayashi K (1994) Mechanical and dimensional adaptation of rat aorta to hypertension. J Biomech Eng 116(3):278-283

Mauri A, Hopf R, Ehret AE, Picu CR, Mazza E (2016) A discrete network model to represent the deformation behavior of human amnion. J Mech Behav Biomed Mater 58:45-56

McEwen BS, Wingfield JC (2010) What is in a name? Integrating homeostasis, allostasis and stress. Horm Behav 57(2):105-111

Miroshnikova YA, Jorgens DM, Spirio L, Auer M, Sarang-Sieminski AL, Weaver VM (2011) Engineering strategies to recapitulate epithelial morphogenesis within synthetic three-dimensional extracellular matrix with tunable mechanical properties. Phys Biol 8(2):026013

Nakagawa Y, Totsuka M, Sato T, Fukuda Y, Hirota K (1989) Effect of disuse on the ultrastructure of the achilles tendon in rats. Eur $\mathrm{J}$ Appl Physiol Occup Physiol 59(3):239-242

Okabe Y, Medzhitov R (2016) Tissue biology perspective on macrophages. Nat Immunol 17(1):9-17

Oria R, Sunyer R, Trepat X, Jones JL, Allen MD, Elosegui-Artola A, Marshall JF, Andreu I, Bazellières E, Gomm JJ, Roca-Cusachs $P$ (2014) Rigidity sensing and adaptation through regulation of integrin types. Nat Mater 13(6):631-637

Orlandi A, Ferlosio A, Gabbiani G, Spagnoli LG, Ehrlich PH (2005) Phenotypic heterogeneity influences the behavior of rat aortic smooth muscle cells in collagen lattice. Exp Cell Res 311(2):317-327

Piolanti N, Polloni S, Bonicoli E, Giuntoli M, Scaglione M, Indelli PF (2018) Giovanni alfonso borelli: the precursor of medial pivot concept in knee biomechanics. Joints 6(3):167-172

Redden RA, Doolin EJ (2003) Collagen crosslinking and cell density have distinct effects on fibroblast-mediated contraction of collagen gels. Skin Res. Technol. 9(3):290-293

Ross TD, Coon BG, Yun S, Baeyens N, Tanaka K, Ouyang M, Schwartz MA (2013) Integrins in mechanotransduction. Curr Opin Cell Biol 25(5):613-618

Sander EA, Barocas VH (2008) Biomimetic collagen tissues: collagenous tissue engineering and other applications. Collagen Struct Mech, pp 475-504

Sander EA, Barocas VH, Tranquillo RT (2011) Initial fiber alignment pattern alters extracellular matrix synthesis in fibroblast-populated fibrin gel cruciforms and correlates with predicted tension. Ann Biomed Eng 39(2):714-729

Sander EA, Stylianopoulos T, Tranquillo RT, Barocas VH (2009) Image-based multiscale modeling predicts tissue-level and network-level fiber reorganization in stretched cell-compacted collagen gels. Proc Natl Acad Sci U S A 106(42):17675-17680

Sawadkar P, Player D, Bozec L, Mudera V (2020) The mechanobiology of tendon fibroblasts under static and uniaxial cyclic load in a 3D tissue engineered model mimicking native extracellular matrix. J Tissue Eng Regen Med 14(1):135-146

Sawhney RK, Howard J (2002) Slow local movements of collagen fibers by fibroblasts drive the rapid global self-organization of collagen gels. J Cell Biol 157(6):1083-1091

Schiller HB, Fässler R (2013) Mechanosensitivity and compositional dynamics of cell-matrix adhesions. EMBO Rep 14(6):509-519

Schiro JA, Chan BMC, Roswit WT, Kassner PD, Pentland AP, Hemler ME, Eisen AZ, Kupper TS (1991) Integrin alpha 2 beta 1 (VLA2 ) mediates reorganization and contraction of collagen matrices by human cells. Cell 67(2):403-410

Schwartz MA (2002) Integrins: emerging paradigms of signal transduction. Annu Rev Cell Dev Biol 11(1):549-599

Sethi KK, Yannas IV, Mudera V, Eastwood M, McFarland C, Brown RA (2002) Evidence for sequential utilization of fibronectin, vitronectin, and collagen during fibroblast-mediated collagen contraction. Wound Repair Regen 10(6):397-408

Sewanan LR, Schwan J, Kluger J, Park J, Jacoby DL, Qyang Y, Campbell SG (2019) Extracellular matrix from hypertrophic myocardium provokes impaired twitch dynamics in healthy cardiomyocytes. JACC Basic to Trans1 Sci 4(4):495-505

Shadwick RE (1999) Mechanical design in arteries. J Exp Biol 202(Pt 23):3305-3313

Simon DD, Horgan CO, Humphrey JD (2012) Mechanical restrictions on biological responses by adherent cells within collagen gels. J Mech Behav Biomed Mater 14:216-226

Simon DD, Humphrey JD (2014) Learning from tissue equivalents: biomechanics and mechanobiology. Bio-inspired Mater. Biomed. Eng. 9781118369:281-308

Simon DD, Niklason LE, Humphrey JD (2014) Tissue transglutaminase, not Lysyl oxidase, dominates early calcium-dependent remodeling of fibroblast-populated collagen lattices. Cells Tissues Organs 200(2):104-117

Stamenović D, Smith ML (2020) Tensional homeostasis at different length scales. Soft Matter 16(30):6946-6963

Steinberg BM, Smith K, Colozzo M, Pollack R (1980) Establishment and transformation diminish the ability of fibroblasts to contract a native collagen gel. J Cell Biol 87(1):304-308

Stevenson MD, Sieminski AL, McLeod CM, Byfield FJ, Barocas VH, Gooch KJ (2010) Pericellular conditions regulate extent of cell-mediated compaction of collagen gels. Biophys J 99(1):19-28

Sukharev S, Sachs F (2012) Molecular force transduction by ion channels-diversity and unifying principles. J Cell Sci 125(13):3075-3083

Thomopoulos S, Fomovsky GM, Chandran PL, Holmes JW (2007) Collagen fiber alignment does not explain mechanical anisotropy in fibroblast populated collagen gels. J Biomech Eng 129(5):642-650

Thomopoulos S, Fomovsky GM, Holmes JW (2005) The development of structural and mechanical anisotropy in fibroblast populated collagen gels. J Biomech Eng 127(5):742-750

Tomasek JJ, Gabbiani G, Hinz B, Chaponnier C, Brown RA (2002) Myofibroblasts and mechano: Regulation of connective tissue remodelling. Nat Rev Mol Cell Biol 3(5):349-363

Wakatsuki T, Kolodney MS, Zahalak GI, Elson EL (2000) Cell mechanics studied by a reconstituted model tissue. Biophys J 79(5):2353-2368

Walker M, Rizzuto P, Godin M, Pelling AE (2020) Structural and mechanical remodeling of the cytoskeleton maintains tensional homeostasis in 3D microtissues under acute dynamic stretch. Sci Rep 10(1):1-16

Watton PN, Hill NA, Heil M (2004) A mathematical model for the growth of the abdominal aortic aneurysm. Biomech Model Mechanobiol 3(2):98-113 
Weaver VM, Petersen OW, Wang F, Larabell CA, Briand P, Damsky C, Bissell MJ (1997) Reversion of the malignant phenotype of human breast cells in three- dimensional culture and in vivo by integrin blocking antibodies. J Cell Biol 137(1):231-245

Weng S, Shao Y, Chen W, Fu J (2016) Mechanosensitive subcellular rheostasis drives emergent single-cell mechanical homeostasis. Nat Mater 15(9):961-967

Weninger W, Csiszar K, Kass L, Erler JT, Yu H, Weaver VM, Yamauchi M, Levental KR, Gasser DL, Fong SFT, Lakins JN, Giaccia A, Egeblad M (2009) Matrix crosslinking forces tumor progression by enhancing integrin signaling. Cell 139(5):891-906

Wolff J (1892) Das Gesetz der Transformation der Knochen. august hirschwald

Wolinsky H, Glagov S (1967) A lamellar unit of aortic medial structure and function in mammals. Circ Res 20(1):99-111

Woodley DT, Yamauchi M, Wynn KC, Mechanic G, Briggaman RA (1991) Collagen telopeptides (cross-linking sites) play a role in collagen gel lattice contraction

Wynn TA, Chawla A, Pollard JW (2013) Macrophage biology in development, homeostasis and disease. Nature 496(7446):445-455

Xie J, Bao M, Bruekers SMC, Huck WTS (2017) Collagen gels with different fibrillar microarchitectures elicit different cellular responses. ACS Appl Mater Interfaces 9(23):19630-19637

Yamato M, Adachi E, Yamamoto K, Hayashi T (1995) Condensation of collagen fibrils to the direct vicinity of fibroblasts as a cause of gel contraction. J Biochem 117(5):940-946
Yeung T, Georges PC, Flanagan LA, Marg B, Ortiz M, Funaki M, Zahir N, Ming W, Weaver V, Janmey PA (2005) Effects of substrate stiffness on cell morphology, cytoskeletal structure, and adhesion. Cell Motil Cytoskeleton 60(1):24-34

Zemel A (2015) Active mechanical coupling between the nucleus, cytoskeleton and the extracellular matrix, and the implications for perinuclear actomyosin organization. Soft Matter 11(12):2353-2363

Zhao X (2014) Multi-scale multi-mechanism design of tough hydrogels: building dissipation into stretchy networks. Soft Matter 10(5):672-687

Zhu C, Pérez-González C, Trepat X, Chen Y, Castro N, Oria R, RocaCusachs P, Elosegui-Artola A, Kosmalska A (2016) Mechanical regulation of a molecular clutch defines force transmission and transduction in response to matrix rigidity. Nat Cell Biol 18(5):540-548

Zhu YK, Umino T, Liu XD, Wang HJ, Romberger DJ, Spurzem JR, Rennard SI (2002) Contraction of fibroblast-containing collagen gels: initial collagen concentration regulates the degree of contraction and cell survival. Vitr Cell Dev Biol - Anim 37(1):10

Publisher's Note Springer Nature remains neutral with regard to jurisdictional claims in published maps and institutional affiliations. 